\title{
Removal and Regeneration of Iron (III) from Water Using New Treated Fluorapatite Extracted from Natural Phosphate as Adsorbent
}

\author{
Rachid El Kaim Billah ${ }^{1, *(\mathbb{D})}$, Younesse Haddaji ${ }^{2, *(\mathbb{D})}$, Otman Goudali ${ }^{1}$, Mahfoud Agunaou ${ }^{1}$, Abdessadik \\ Soufiane ${ }^{1}$ \\ 1 Department of Chemistry, University of Chouaib Doukkali, Faculty of Sciences, Laboratory of Coordination and \\ Analytical Chemistry, (El Jadida) Morocco \\ 2 Department of Chemistry, University of Hassan II-Casablanca, Faculty of Sciences Ben M'Sik, Laboratory of engineering \\ and materials (Casablanca) Morocco \\ * Correspondence: rachidelkaimbillah@gmail.com;
}

Scopus Author ID 57208011888

Received: 6.01.2021; Revised: 28.01.2021; Accepted: 30.01.2021; Published: 7.02.2021

\begin{abstract}
Our study aims to evaluate the efficiency of dissolved iron (III) retention in synthetic solutions by adsorption on treated natural phosphate collected in the Khouribga region. This research focused on the valorization of phosphate, a naturally occurring resource that is abundant in Morocco. The resulting products were analyzed by various methods, including FT-IR spectroscopy, X-ray diffraction (XRD) and scanning electron microscopy (SEM). In this work, we studied the effect of several parameters such as adsorbent amount, contact time, solution $\mathrm{pH}$, and initial concentration of iron (III) on the adsorption process. The results of the adsorption of iron (III) indicate that the efficiency was achieved after 5 minutes, and the maximum adsorption capacity calculated from the Langmuir model was $26.18 \mathrm{mg}$ g-1. The regeneration and reuse of synthesized adsorbent are effective for five cycles of adsorption-desorption cycles without reducing adsorption capacity.
\end{abstract}

Keywords: natural phosphate; floroapatite; adsorption; iron (III); regeneration.

(C) 2021 by the authors. This article is an open-access article distributed under the terms and conditions of the Creative Commons Attribution (CC BY) license (https://creativecommons.org/licenses/by/4.0/).

\section{Introduction}

Iron is an essential mineral. It can cause serious health problems at high levels such as stomach cramps, skin irritations, vomiting, nausea, and anemia [1]. The World Health Organization (WHO) has limited iron in drinking water of about $2 \mathrm{mg} \mathrm{L}-1$ to limit a health risk [2].

The most important sources of contamination classify in urban activities, industrial waste, and fertilizers. Researchers use several literature techniques to solve this problem: electroplating, reverse osmosis, lime treatment, ion exchange, and adsorption [3,4].

In recent years, researchers have recognized adsorption as an effective method for reducing metal contamination in surface waters and industrial effluents [5] and especially for effluents contaminated by iron (III)[6]. Many sorbents have been reported for the removal of iron (III) ions from aqueous solutions, such as natural a-Alumina [7], Chelation Resin [8], di(2ethylhexyl) phosphate [9], poly (para-methoxystyrene) [10], activated carbon developed [11], graphene oxide [12], fluorescent hydrogel [13], cross-linked polystyrene [14], thiosalcylic acid [15],nano-CA particles [16], However, in the last few years, the interest is directed to the use of natural products, such as apatite 
Apatite is the most abundant phosphate mineral on earth, showing excellent thermodynamic stability [17]. Indeed, in a natural environment, all calcium phosphates evolve towards the apatite structure. They are one of the principal constituents of the bones and teeth of all vertebrates. The use of apatite to confine heavy metals is part of research into polluting waste's mineralogical storage.

Moroccan natural phosphates are essentially sedimentary. Phosphated rocks consist mainly of fluorapatite $\left(\mathrm{Ca} 5\left(\mathrm{PO}_{4}\right)_{3} \mathrm{~F}\right)$, which is weakly crystallized and widely used due to its adsorption and ionic exchange properties. The presence of minerals such as calcite and dolomite in sedimentary apatite is very beneficial for phosphorus retention due to the good dissolution of these carbonated minerals. This results in an increase in the reaction medium's $\mathrm{pH}$ and the concentration of $\mathrm{Ca} 2+$ ions in the solution, promoting calcium phosphate precipitation [17]. Apatite has been used extensively due to its high capacity to immobilize various heavy metals such as $\mathrm{Cd}^{2+}, \mathrm{Pb}^{2+}, \mathrm{Cu}^{2+}[18]$.

The proposed exchange mechanisms are different depending on the element under consideration and natural conditions. We found ion exchanges (exchanges on cationic sites of $\mathrm{Ca}^{2+}$ ) associated with diffusion in the apatitic structure. During this process, the ion radius and electronegativity of the metal ion are the main parameters of this mechanism $[19,20]$. Have shown that ions with a higher ion radius than calcium $(0.99 \AA)$ are best incorporated into the apatite network.

In this work, two objectives were taken into account. The treatment of Moroccan rock phosphate firstly by thermal treatment then activation with $\mathrm{HNO}_{3}$, while optimizing the synthesis parameters to obtain nanoparticles of calcium phosphate of apatitic structure. This approach is the original focus of our work to eliminate iron (III). The second objective is to eliminate dissolved Iron (III) in synthetic solutions by adsorption on treated phosphate to valorize the product, which is abundant in the Khouribga-Morocco region. The material obtained was characterized by infrared spectroscopy (FTIR), X-ray diffraction (DRX), thermal analysis (ATG/ATD), and scanning electron microscopy (SEM). The adsorption capacity of Iron (III) was calculated using the ICP technique.

\section{Materials and Methods}

\subsection{Materials.}

The chemicals products used in this study were: iron trichloride hexahydrate $\left(\mathrm{FeCl}_{3} .6 \mathrm{H}_{2} \mathrm{O}\right)$ with a purity of $\geq 99 \%$, sodium hydroxide $(\mathrm{NaOH})$ with a purity of $\geq 99 \%$, hydrochloric acid $(\mathrm{HCl})$ with a purity of $37 \%$, nitric acid $\left(\mathrm{HNO}_{3}\right)$ with a purity of $65 \%$, and ammonia $\left(\mathrm{NH}_{3}\right)$ with a purity of $\geq 99 \%$. These products were purchased from Sigma Aldrich.

\subsection{Adsorbents preparation.}

A sample of raw rock phosphate was washed at a temperature of $70^{\circ} \mathrm{C}$ for 3 hours, dried at a temperature of $100^{\circ} \mathrm{C}$, calcined for two hours at a temperature of $1000^{\circ} \mathrm{C}$, and finally activated with $15 \mathrm{ml}$ of concentrated nitric acid $\mathrm{HNO}_{3}(65 \%)$. The reaction mixture is maintained under continuous agitation with a magnetic stirrer for an optimal period of 2 hours at room temperature. The precipitate is filtered under vacuum, washed with distilled water, dried for 24 hours in an oven at $100{ }^{\circ} \mathrm{C}$, and ground to a particle size of less than $125 \mu \mathrm{m}$. 


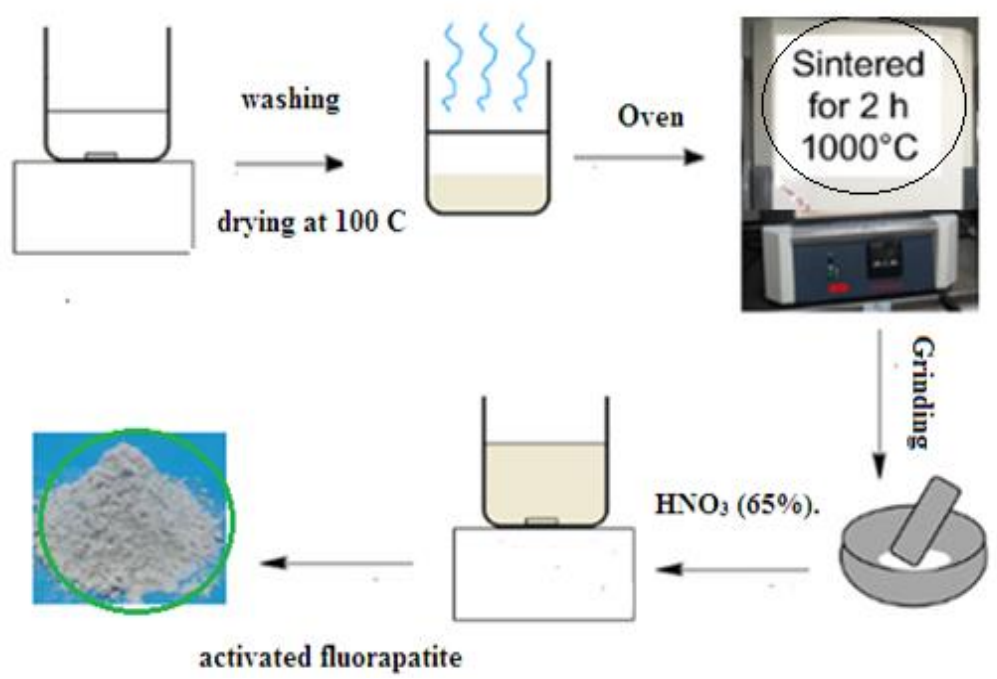

Figure 1. Schematic demonstration of adsorbent preparation steps.

\subsection{Characterizations.}

X-Rays Diffraction analysis was carried out using a Bruker D8 diffractometer operating at $45 \mathrm{kV} / 100 \mathrm{~mA}$, using CuKa radiation with Ni filter. The samples' surface morphology was obtained from scanning electron microscopy (SEM) Philips XL 30 ESEM (Acc spot Magn $20.00 \mathrm{kv}$ ). FT-IR spectrometer was obtained using a Thermo-scientific Spectrometer in the mid-infrared region between 400 and $4000 \mathrm{~cm}^{-1}$ with a resolution of $4 \mathrm{~cm}^{-1}$.

\subsection{Adsorption studies.}

An iron (III) stock solution is prepared at a concentration of $1000 \mathrm{mg} / \mathrm{L}$ by dissolving a suitable mass of $(\mathrm{FeCl} 3.6 \mathrm{H} 2 \mathrm{O})$ in distilled water. The following steps were carried out in 100 $\mathrm{ml}$ beakers and balanced using a magnetic stirrer. We studied the effect of the main parameters such as the adsorbent weight ( 1 to $10 \mathrm{~g}$ ), initial solution $\mathrm{pH}$ ( 1 to 7 ), contact time (1 to $15 \mathrm{~min}$ ), initial concentration (20 to $100 \mathrm{mg} \mathrm{L}-1)$ in solution, and temperature $\left(15-35^{\circ} \mathrm{C}\right.$ ) on the adsorption capacity of treated phosphate in a solution containing $50 \mathrm{ml}$ of iron (III). After the adsorption process, the suspensions were filtered through a filter. Induction Coupled Plasma Atomic Emission Spectrometry (ICP-AES) analyzed the concentration of iron (III) in the filtrate.

The equilibrium adsorption capacity (qe) was calculated according to the following equation:

$$
\begin{aligned}
& q_{t}=\frac{\left(C_{0}-C_{t}\right) V}{m} \\
& \% \text { Removal }=\frac{\left(C_{0}-C_{t}\right)}{C_{0}} \times 100
\end{aligned}
$$

where $\mathrm{C}_{\mathrm{o}}$ and $\mathrm{C}_{\mathrm{t}}$ are the amounts of initial and retained iron(III) in the solution at time $\mathrm{t}(\mathrm{mg} / \mathrm{L})$, respectively; $\mathrm{V}$ is the solution volume $(\mathrm{L})$, and $\mathrm{m}$ is the mass of adsorbent $(\mathrm{g})$.

\subsection{Data analysis.}

To describe the mechanism involved in the adsorption process, the experimental kinetic data were analyzed by application of the pseudo-first-order and the pseudo-second-order. At the same time, Langmuir and Freundlich's models were used to describe the obtained isotherms to propose the sorption mechanism involved (Table 1). Thermodynamic parameters including the Gibbs free energy $(\Delta \mathrm{G})$, enthalpy $(\Delta \mathrm{H})$, and entropy $(\Delta \mathrm{S})$ were also analyzed to predict the 
feasibility and determine the nature of the adsorption process in the temperature range of 25 $45{ }^{\circ} \mathrm{C}$.

\section{Results and Discussion}

\subsection{Characterizations.}

\subsubsection{X-Rays Diffraction.}

Figure 2 shows the X-ray diffractogram of the raw and treated fluorapatite. In the case of treated phosphate, the results show that phosphate solids crystallize in the $63 / \mathrm{m}$ P hexagonal spacegroup system. They consist of a fluorapatite structure, as the main component, accompanied by $\mathrm{SiO}_{2}$. Similar DRX diagrams have been identified for other Moroccan natural phosphates, such as Khouribga [20] and Youssoufia [21] deposits.

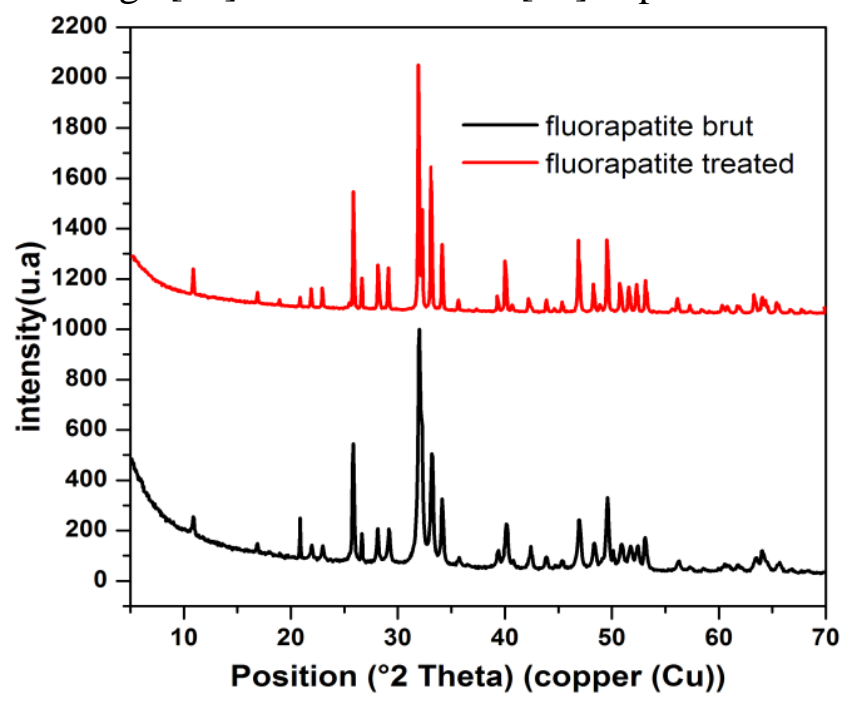

Figure 2. X-ray patterns of natural and treated fluorapatite.

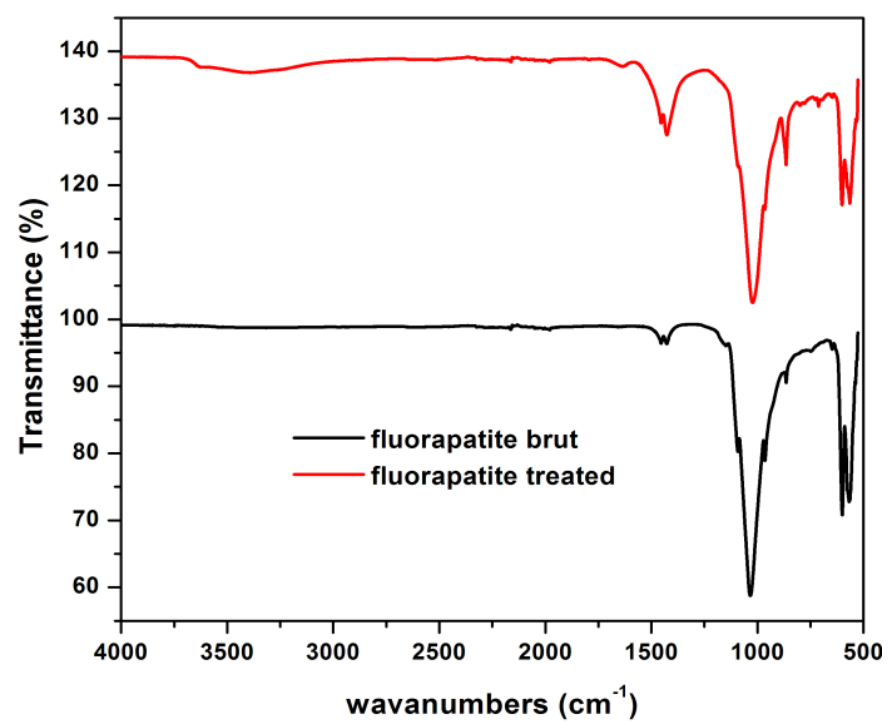

Figure 3. FTIR spectra of natural and treated fluorapatite.

\subsubsection{FTIR Analysis.}

Figure 3 shows the infrared spectra of natural and treated fluorapatite. The IR absorption bands of natural and treated fluorapatite are due to the vibrations of $\mathrm{PO}^{3-}, \mathrm{OH}^{-}$and 
$\mathrm{CO}_{3}{ }^{2-}$ ions. The natural fluorapatite had a band at $3570.57 \mathrm{~cm}^{-1}$, corresponding to the $\mathrm{OH}^{-}$. Both had bands related to $\mathrm{PO}_{4}{ }^{-3}$ stretching and bending at 1042, 602, and $567 \mathrm{~cm}^{-1}$, indicating apatite structure [22]. The bands located at $1413.57 \mathrm{~cm}^{-1}$ and $1455.03 \mathrm{~cm}^{-1}$ are assigned to the $\mathrm{CO}^{2-}$ [23]. The disappeared band in the treated fluorapatite was assigned to the carbonates band.

\subsubsection{Scanning Electronic Microscopy.}

The scanning electron microscope (SEM) analysis shows that the natural phosphate, which is beige in color, is composed essentially of irregularly shaped or rounded phosphate particles, bone debris, organic debris, and quartz grains [24]. Existing nodules show a concentric structure, marked by variations in the concentration of organic matter on the surface of the grains, but that after calcination (Figure 4-b), the shape has been modified. Fluorapatite particles appear to be formed by aggregating submicrometric crystals in the form of needles, while these crystals form intermediate aggregates [25]. However, these data suggest that the heat treatment of fluorapatite impacts the aggregation of particle growth.
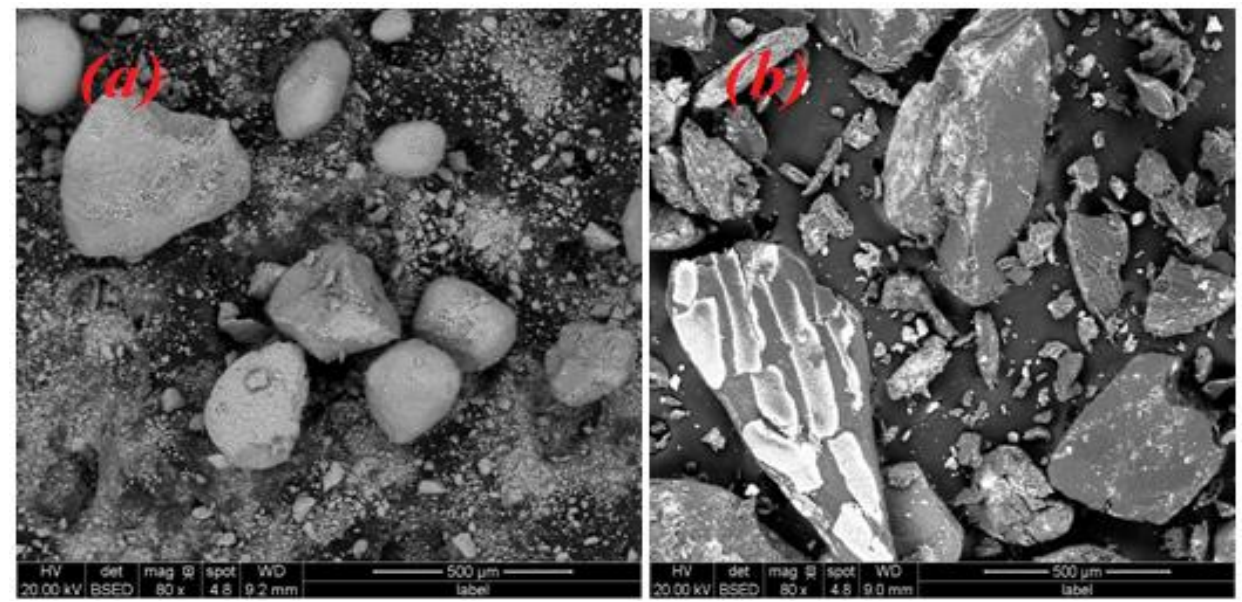

Figure 4. SEM of (a) natural; (b) treated fluorapatite.

\subsection{Adsorption studies.}

\subsubsection{The effect of $\mathrm{pH}$.}

Figure 5 illustrates that the efficiency of Iron (III) elimination increases with increasing $\mathrm{pH}$ from 1 to 3 . In the current study, the removal achieved $99.8 \%$ at $\mathrm{pH}=3$. After that, the removal efficiency of Iron (III) remains constant. Therefore, we conclude that the $\mathrm{pH}$ value affects the iron (III) removal mechanism by treated fluorapatite. The optimal $\mathrm{pH}$ for further experiments was 3 .

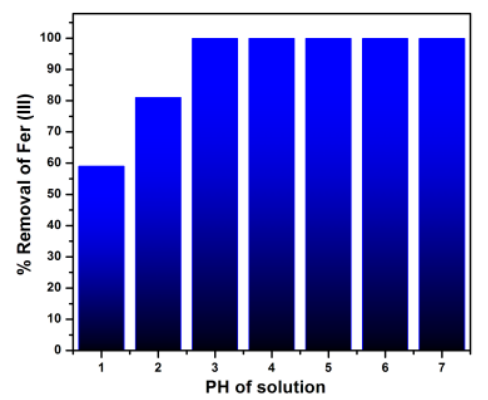

Figure 5. Effect of initial pH solution on removal efficiency of iron (III) using treated fluorapatite. (experimental conditions: $\mathrm{C}$ (iron (III)) $=100 \mathrm{mg} / \mathrm{l}$, contact time $=10 \mathrm{~min}$, adsorbent weigh $=0.25 \mathrm{~g}$, and $\left.\mathrm{T}^{\circ}=25^{\circ} \mathrm{C}\right)$. 


\subsubsection{The effect of adsorbent mass.}

The curve in Figure 6 shows that the quantity of iron (III) adsorbed by treated fluorapatite is more important as the adsorbent's quantity increased. This is explained by the availability of active sites on the adsorbent material's surface, which can fix iron ions (III). Above a quantity of $5 \mathrm{~g}$, we can see that the removal efficiency of residual iron (III) remains practically steady.

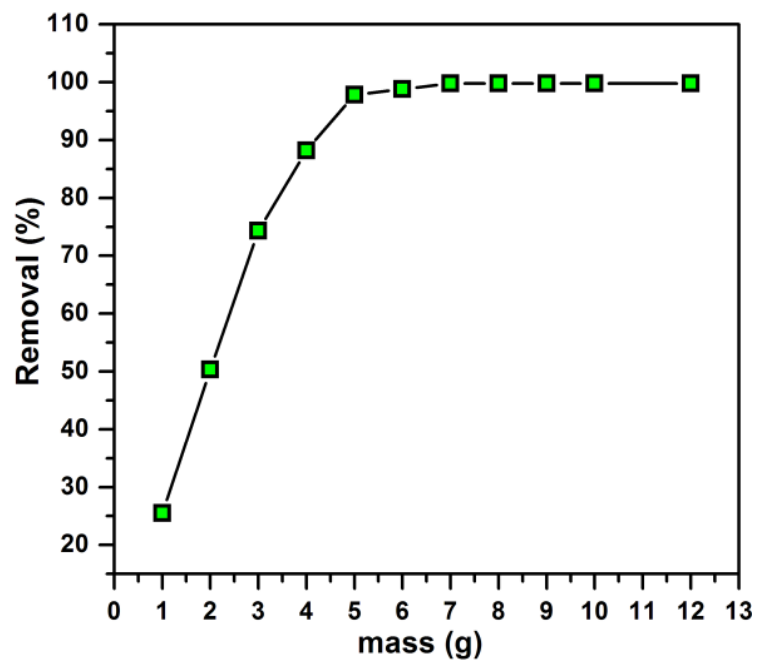

Figure 6. Effect of adsorbent weight on the removal efficiency of iron (III). (experimental conditions: $\mathrm{C}$ (iron $(\mathrm{III})=100 \mathrm{mg} / \mathrm{l}, \mathrm{PH}=3$, contact time $\left.=10 \mathrm{~min}, \mathrm{~T}^{\circ}=25^{\circ} \mathrm{C}\right)$.

\subsubsection{Adsorption kinetics.}

Figure 7 demonstrates the contact time impact on the removal efficiency of the iron (III) ions on treated fluorapatite. The obtained results show that iron (III) ions' removal rate increases with increasing contact time until saturation. This is due to the availability of active sites available on the adsorbent material's surface until reaching an adsorption equilibrium where all sites become occupied and reveal a similar behavior towards the Iron (III) ions.

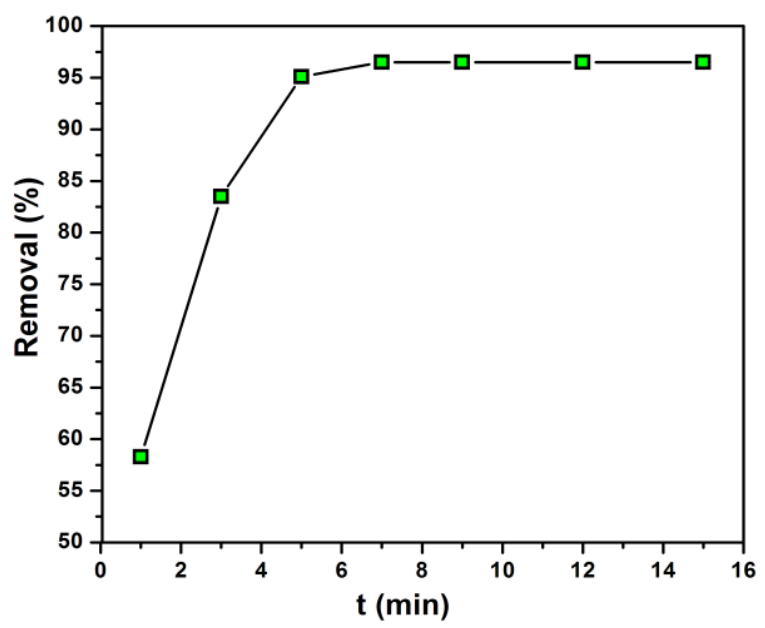

Figure 7. Effect of contact time on the removal iron (III) by treated fluorapatite. (experimental conditions: C $($ iron $\left.(\mathrm{III}))=100 \mathrm{mg} / \mathrm{l}, \mathrm{m}=0.25 \mathrm{~g}, \mathrm{ph}=3, \mathrm{~T}^{\circ}=25^{\circ} \mathrm{C}\right)$.

\subsubsection{Concentration effect.}

From the illustration, it can be noted that the rate of removal of Iron (III) ions decreases with increasing metal concentration. The increase in Iron (III) concentration from 20 to 100 $\mathrm{mg} / \mathrm{l}$ would decrease the percentage of elimination. 


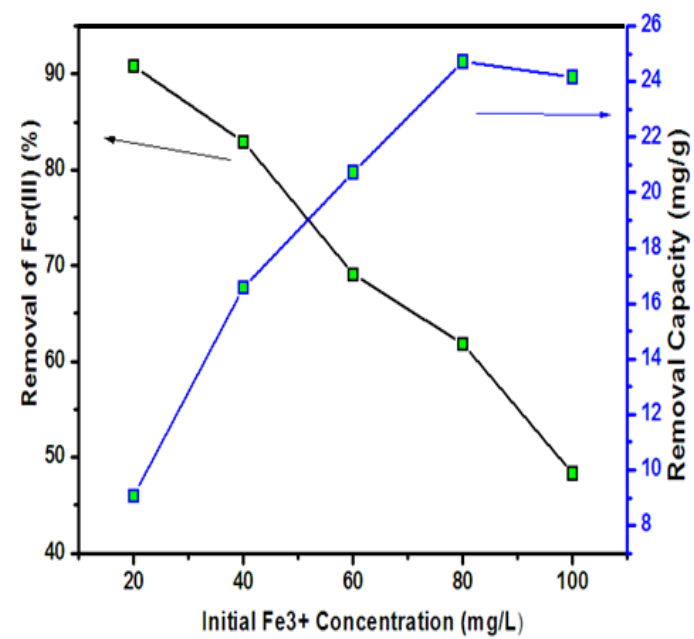

Figure 8. influence of initial concentration on the removal of iron (III) by treated fluorapatite. (Experimental conditions: $\mathrm{pH}=3, \mathrm{~m}=0.1 \mathrm{~g}$, time $\left.=10 \mathrm{~min}, \mathrm{~T}^{\circ}=25^{\circ} \mathrm{C}\right)$.

\subsection{Kinetic models.}

\subsubsection{Pseudo-first-order kinetic model.}

To examine the adsorption mechanism, we determined the rate constants $\mathrm{K} 1$, the equilibrium adsorption capacity $\left(\mathrm{q}_{\mathrm{e}}\right)$, and the correlation coefficients $\left(\mathrm{R}^{2}\right)$ obtained by plotting $\log \left(\mathrm{q}_{\mathrm{e}}-\mathrm{q} \mathrm{t}\right)$ as a function of time.

The following equations express the linear forms of the pseudo-first-order model [26]:

$$
\log \left(\mathrm{q}_{\mathrm{e}}-\mathrm{q}_{\mathrm{t}}\right)=\log \mathrm{q}_{\mathrm{e}}-\mathrm{k}_{1} \mathrm{t} / 2.303
$$

Table 1 shows that the experimental points' correlation coefficient is $97.2 \%$, and the values of qe calc $i$ are far from experimental values qe, exp. The values suggest that the iron (III) ion adsorption kinetics did not fit well with the first pseudo-order model.

\subsubsection{Pseudo-second order kinetic model.}

We also tested the pseudo-second-order [27] kinetic model in its linearized form. The plot of $t / q t$ versus $t$ made it possible to calculate the rate constants $K_{2}$, the equilibrium adsorption capacity $\left(\mathrm{q}_{\mathrm{e}}\right)$, and the correlation coefficients $\left(\mathrm{R}^{2}\right)$ (Table 1$)$.

The linear forms of the pseudo-second-order [25] are given by the following equations:

$$
\mathrm{t} / \mathrm{qt}=1 / \mathrm{k} 2 . \mathrm{qe} 2+\mathrm{t} / \mathrm{qe}
$$

The high correlation coefficients $\left(\mathrm{R}^{2} \geq 0.998\right)$ and the small difference between the values of $\mathrm{q}_{\mathrm{e}}$.
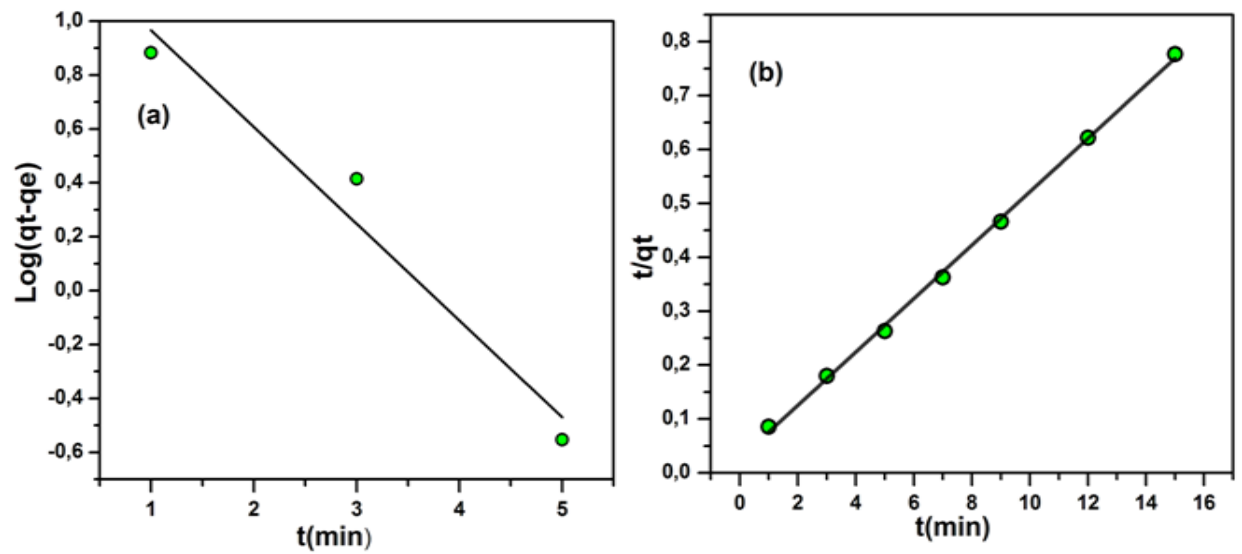

Figure 9. Kinetic studies by (a) pseudo-first-order model; (b) pseudo-second-order model. 
Table 1. Kinetics adsorption parameters of iron (III) onto treated fluorapatite (Fap).

\begin{tabular}{c|c|c|c|c|c|c|c} 
& & \multicolumn{3}{|c|}{ Pseudo-First-Order model } & \multicolumn{4}{c}{ Pseudo-Second-Order } \\
model
\end{tabular}

\subsection{Isotherm models.}

\subsubsection{Langmuir Isotherm.}

The Langmuir model is [28] calculated by the equation (3). The plot of 1/qe versus Ce is used to determine the Langmuir constant isotherm. The values of $\mathrm{Q}_{\mathrm{m}}$ and $\mathrm{K}_{1}$ are calculated and listed in Table 3.

$$
1 / q_{e}=1 / q_{m}+1 / q_{m} K_{1} C_{e}
$$

It can be seen (Table 3$)$ that the correlation coefficient $\left(\mathrm{R}^{2}=0.99\right)$ of the Langmuir model is very close to one. This good correlation between the adsorption data and the Langmuir model indicates the fluorapatite surface's homogeneous nature.

The shape of the isotherm allows predicting whether the adsorption is favorable. This property is expressed by the dimensionless separator factor $\mathrm{R}_{\mathrm{L}}$, with the equation:

$$
\mathrm{R}_{\mathrm{L}}=1 /\left(1+\mathrm{K}_{1} \mathrm{C}_{0}\right)
$$

Where $\mathrm{K}_{1}$ is thermodynamic Langmuir constants and $\mathrm{C}_{0}$ is the concentration of the initial solution

The $R_{L}$ values indicate whether the system is irreversible $\left(R_{L}=0\right)$, favorable $\left(0<R_{L}<1\right)$, linear $\left(R_{L}=1\right)$, or unfavorable $\left(R_{L}>1\right)$. The $R_{L}$ values are presented in Table 2 .

The calculated value of $R_{L}$ is 0.03 for treated fluorapatite, indicating that adsorption is favorable.

\subsubsection{Freundlich Isotherm.}

The Freundlich model [29] is determined by the following equation after linearization.

$$
\log q_{e}=\log K_{F}+1 / n \log C_{e}
$$

By plotting the $\log$ qe curve as a function $\log \mathrm{Ce}$, we obtain the Freundlich constant 1/n $\mathrm{K}_{\mathrm{F} .} \mathrm{n}$ is an empirical constant related to the value of adsorption intensity, and $\mathrm{K}_{\mathrm{F}}$ is a constant indicating the adsorption capacity. The numerical value of $1 / \mathrm{n}=0.3$ (Table 2 ) indicates that the adsorption is favorable.
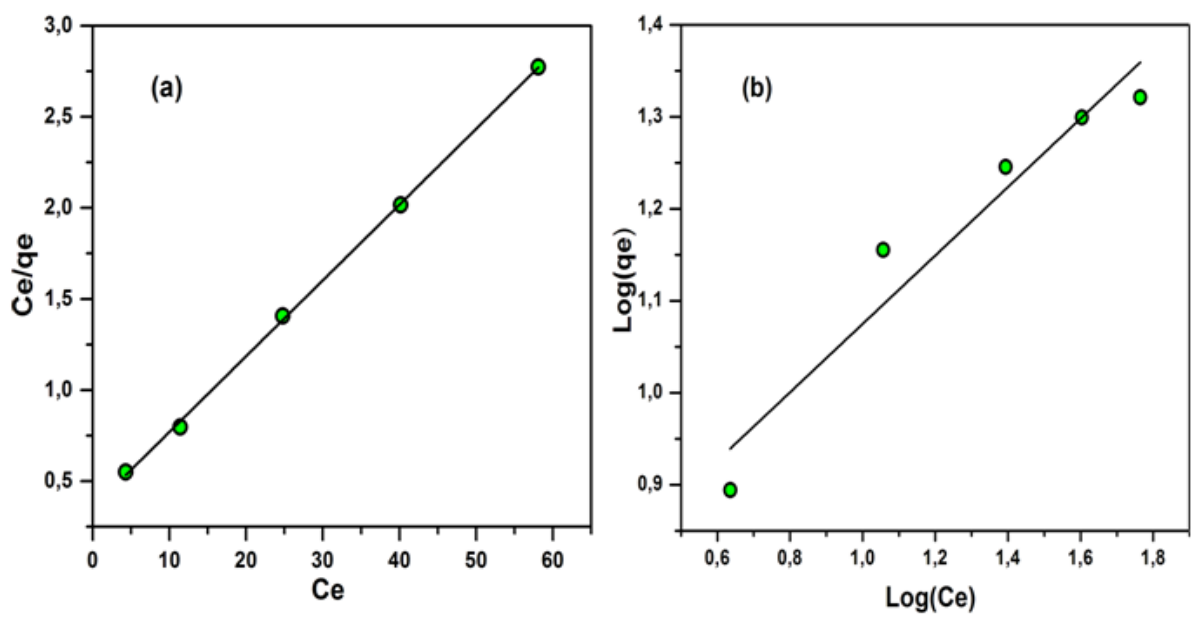

Figure 10. Linear Representations of the (a) Freundlich; (b) Langmuir model for the adsorption of iron (III) ion treated fluorapatite. 
Table 2. Constants of the Langmuir and Freundlich models.

\begin{tabular}{|c|c|c|c|c|c|c|}
\hline & \multicolumn{3}{|c|}{ Langmuir } & \multicolumn{3}{|c|}{ Freundlich } \\
\hline & $\begin{array}{l}\text { Qmax } \\
(\mathrm{mg} / \mathrm{g})\end{array}$ & $\begin{array}{l}\mathrm{K}_{\mathrm{L}} \\
\left(\mathrm{L} \cdot \min ^{-1}\right)\end{array}$ & $\mathrm{R}^{2}$ & $\begin{array}{l}\mathrm{K}_{\mathrm{F}} \\
(\mathrm{mg} / \mathrm{g})\end{array}$ & $1 / n$ & $\mathrm{R}^{2}$ \\
\hline FAP & 12.18 & 0.27 & 0.999 & 5 & 0.3 & 0.94 \\
\hline
\end{tabular}

\subsection{Regeneration.}

Regeneration is an important parameter. To know the recycling efficiency and reusability of FapA, the reusability was studied using $100 \mathrm{mg}$ Fap treated with iron (III) and $50 \mathrm{ml}$ of $0.5 \mathrm{NaOH}$ when shaking for 1 hour, then recycled Fap was filtered and washed. Sorption regeneration was repeated 6 times. After 5 cycles, performance decreased by $18.4 \%$. These tests revealed that Fap could be effectively used as an adsorbent for the total removal of Iron(III) from aqueous solutions.

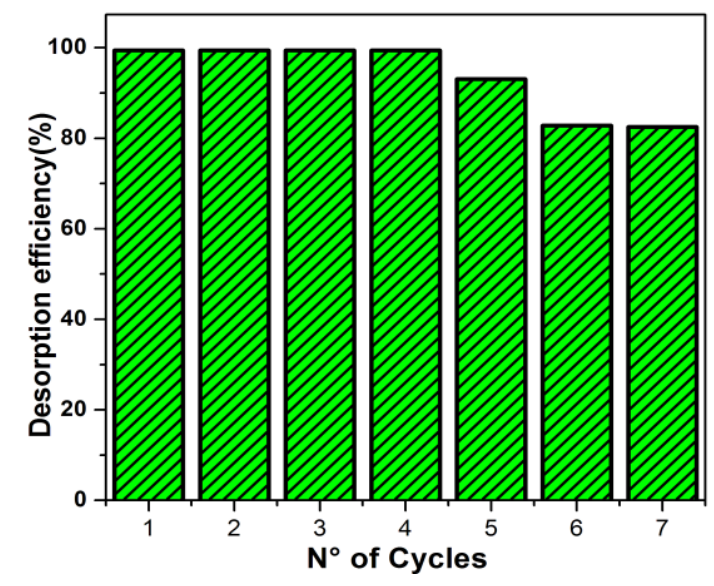

Figure 11.Renewability of iron(III) ions onto Fap.

\section{Conclusions}

Our work's objective was to evaluate and explain iron (III) retention by treated fluorapatite. Results demonstrated that iron (III) retention by treated fluorapatite is rapid; 5 min is sufficient to achieve the adsorbent/adsorbate equilibrium. The amount of adsorbed iron (III) used in this equilibrium study is all the more important, as the amount of adsorbent is high, the amount of iron (III) adsorbed on treated phosphate increases with increasing $\mathrm{pH}$, the modeling of experimental isotherms shows that for the adsorption of iron (III) by treated phosphates, adsorption is efficient at low concentrations. It becomes more difficult for the adsorbate when its concentration increases. The best description of the experimental data is obtained with Langmuir models. It can be concluded that Khouribga Phosphate treatment can improve the removal of iron (III) ion levels.

\section{Funding}

This research received no external funding

\section{Acknowledgments}

The authors gratefully thank Chemistry Department of the Faculty of Sciences of The University of Chouaib Doukkali. 


\section{Conflicts of Interest}

The authors declare no conflict of interest.

\section{References}

1. Cheng, Z.; Yan, M.; Cao, L.; Huang, J.; Cao, X.; Yuan, D.; Chen, Y. Design of Nitrile Rubber with High Strength and Recycling Ability Based on Fe3+-Catechol Group Coordination. Ind. Eng. Chem. Res. 2019, 58, 3912-3920, https://doi.org/10.1021/acs.iecr.8b05993.

2. Chaturvedi, S.; Dave, P.N. Removal of iron for safe drinking water. Desalination 2012, 303, 1-11, https://doi.org/10.1016/j.desal.2012.07.003.

3. Barhoumi, A.; Ncib, S.; Bouguerra, W.; Hamrouni, B.; Elaloui, E. Combining adsorption on activated carbon with electrocoagulation process for copper removal from used water. Desalination and Water Treatment 2017, 83, 212-221, https://doi.org/10.5004/dwt.2017.20984.

4. Wu, K.; Li, Y.; Liu, T.; Huang, Q.; Yang, S.; Wang, W.; Jin, P. The simultaneous adsorption of nitrate and phosphate by an organic-modified aluminum-manganese bimetal oxide: Adsorption properties and mechanisms. Appl. Surf. Sci. 2019, 478, 539-551, https://doi.org/10.1016/j.apsusc.2019.01.194.

5. Goudali, O.; El Kaimbillah, R.; Agunaou, M.; El Azhar, M.; Soufiane, A. Comparative Study of Adsorption of Fluoride Ions on Chitosan Gel Beads and Cross-Linked Chitosan Gel Beads. Egyptian Journal of Chemistry 2020, 63, 4253-4259, doi:10.21608/ejchem.2019.12621.1795.

6. Pakuła, M.; Biniak, S.; Świạtkowski, A. Chemical and Electrochemical Studies of Interactions between Iron(III) Ions and an Activated Carbon Surface. Langmuir 1998, 14, 3082-3089, https://doi.org/10.1021/la9705625.

7. Rajabzadeh, M.; Aghaie, H.; Bahrami, H. Thermodynamic study of Iron (III) removing by the synthesized $\alpha$ Alumina powder and evaluating the corresponding adsorption isotherm models using Response Surface Method. Arabian Journal of Chemistry 2020, 13, 4254-4262, https://doi.org/10.1016/j.arabjc.2019.07.006.

8. Lv, R.; Hu, Y.; Jia, Z.; Li, R.; Zhang, X.; Liu, J.; Fan, C.; Feng, J.; Zhang, L.; Wang, Z. Removal of Iron(III) and Aluminum Ions from Phosphoric Acid-Nitric Acid Solutions by S957 Chelation Resin: Kinetics, Dynamic Adsorption, and Elution. Ind. Eng. Chem. Res. 2019, 58, 21641-21648, https://doi.org/10.1021/acs.iecr.9b04682.

9. Hu, G.; Wu, Y.; Chen, D.; Wang, Y.; Qi, T.; Wang, L. Selective removal of iron(III) from highly salted chloride acidic solutions by solvent extraction using di(2-ethylhexyl) phosphate. Frontiers of Chemical Science and Engineering 2020, https://doi.org/10.1007/s11705-020-1955-4.

10. Liao, G.; Zhong, L.; Cheung, C.S.; Du, C.; Wu, J.; Du, W.; Zheng, H.; Gao, H. Direct synthesis of hypercrosslinked microporous poly(para-methoxystyrene) for removal of iron(III) ion from aqueous solution. Microporous Mesoporous Mater. 2020, 307, 110469, https://doi.org/10.1016/j.micromeso.2020.110469.

11. Das, S.; Mishra, S. Insight into the isotherm modelling, kinetic and thermodynamic exploration of iron adsorption from aqueous media by activated carbon developed from Limonia acidissima shell. Mater. Chem. Phys. 2020, 245, 122751, https://doi.org/10.1016/j.matchemphys.2020.122751.

12. Kang, Y.-G.; Chi Vu, H.; Chang, Y.-Y.; Chang, Y.-S. Fe(III) adsorption on graphene oxide: A low-cost and simple modification method for persulfate activation. Chem. Eng. J. 2020, 387, 124012, https://doi.org/10.1016/j.cej.2020.124012.

13. Zhang, D.; Tian, X.; Li, H.; Zhao, Y.; Chen, L. Novel fluorescent hydrogel for the adsorption and detection of Fe (III). Colloids Surf. Physicochem. Eng. Aspects 2021, 608, 125563, https://doi.org/10.1016/j.colsurfa.2020.125563.

14. Dardouri, M.; Ammari, F.; BelHadj Amor, A.; Meganem, F. Adsorption of cadmium (II), zinc (II) and iron (III) from water by new cross-linked reusable polystyrene adsorbents. Mater. Chem. Phys. 2018, 216, 435445, https://doi.org/10.1016/j.matchemphys.2018.06.002.

15. El-Hamid, A.; Aly, H.F. Removal of Fe (III) from aqueous solution using thiosalcylic acid as an efficient adsorbent. Egyptian Journal of Chemistry 2018, 61, 617-627, https://doi.org/10.21608/ejchem.2018.3312.1280.

16. El-Dafrawy, S.M.; Youssef, H.M.; Toamah, W.O.; El-Defrawy, M.M. Synthesis of Nano-CaO Particles and Its Application for the Removal of Copper (II), Lead (II), Cadmium (II) and Iron (III) from Aqueous Solutions. Egyptian Journal of Chemistry 2015, 58, 579-589, https://doi.org/10.21608/ejchem.2015.1007. 
17. Meski, S.; Tazibt, N.; Khireddine, H.; Ziani, S.; Biba, W.; Yala, S.; Sidane, D.; Boudjouan, F.; Moussaoui, N. Synthesis of hydroxyapatite from mussel shells for effective adsorption of aqueous Cd(II). Water Sci. Technol. 2019, 80, 1226-1237, https://doi.org/10.2166/wst.2019.366.

18. Varaprasad, K.; Nunez, D.; Yallapu, M.M.; Jayaramudu, T.; Elgueta, E.; Oyarzun, P. Nano-hydroxyapatite polymeric hydrogels for dye removal. RSC Advances 2018, 8, 18118-18127, https://doi.org/10.1039/C8RA01887A.

19. Li, Z.; Li, M.; Zheng, T.; Li, Y.; Liu, X. Removal of tylosin and copper from aqueous solution by biochar stabilized nano-hydroxyapatiter Chemosphere $\quad \mathbf{2 0 1 9}, \quad 235, \quad$ 136-142, https://doi.org/10.1016/j.chemosphere.2019.06.091.

20. Billah, R.E.K.; Elyamani, Y.; Rakhila, Y.; Agunaou, M.; Soufiane, A. Removal of Cr (VI) from aqueous solution by adsorption on the natural and activated fluorapatite. 2019, 12, 8, 10.31788/RJC.2019.1215078

21. Salim, N.A.A.; Puteh, M.H.; Yusoff, A.R.M.; Abdullah, N.H.; Fulazzaky, M.A.; Arman, M.; Khamidun, M.H.; Zaini, M.A.A.; Syafiuddin, A.; Ahmad, N. Adsorption isotherms and kinetics of phosphate on waste mussel shell. MJFAS 2020, 16, 393-399.

22. Hajar Saharudin, S.; Haslinda Shariffuddin, J.; Ida Amalina Ahamad Nordin, N.; Ismail, A. Effect of Aging Time in the Synthesis of Biogenic Hydroxyapatite Derived from Cockle Shell. Materials Today: Proceedings 2019, 19, 1208-1215, https://doi.org/10.1016/j.matpr.2019.11.124.

23. Berzina-Cimdina, L.; Borodajenko, N. Research of calcium phosphates using Fourier transform infrared spectroscopy. Infrared spectroscopy-materials science, engineering and technology 2012, 12, 251-263, https://doi.org/10.5772/36942.

24. Coelho, C.C.; Grenho, L.; Gomes, P.S.; Quadros, P.A.; Fernandes, M.H. Nano-hydroxyapatite in oral care cosmetics: characterization and cytotoxicity assessment. Sci. Rep. 2019, 9, 11050, https://doi.org/10.1038/s41598-019-47491-Z.

25. Billah, R.E.K.; Abdellaoui, Y.; Anfar, Z.; Giácoman-Vallejos, G.; Agunaou, M.; Soufiane, A. Synthesis and Characterization of Chitosan/Fluorapatite Composites for the Removal of Cr (VI) from Aqueous Solutions and Optimized Parameters. Water Air Soil Pollut 2020, 231, 163, doi:10.1007/s11270-020-04535-9.

26. Naveen Kumar Reddy, B.; Kiran, P. Effect of silver oxide on hydroxy carbonated apatite formation for simulated body fluid soaked calcium phospho silicate system. Materials Today: Proceedings 2019, 19, 26132616, https://doi.org/10.1016/j.matpr.2019.10.097.

27. Revellame, E.D.; Fortela, D.L.; Sharp, W.; Hernandez, R.; Zappi, M.E. Adsorption kinetic modeling using pseudo-first order and pseudo-second order rate laws: A review. Cleaner Engineering and Technology 2020, 1, 100032, https://doi.org/10.1016/j.clet.2020.100032.

28. Guo, X.; Wang, J. Comparison of linearization methods for modeling the Langmuir adsorption isotherm. $J$. Mol. Liq. 2019, 296, 111850, https://doi.org/10.1016/j.molliq.2019.111850.

29. Li, L.; Qiao, Q.; Zhou, G.; Qi, Y.; Lim, Z.H.; Chau, F.S.; Zhou, G. Design of an on-chip Fourier transform spectrometer based on waveguide Mach-Zehnder Interferometer and fluidics. Opt. Commun. 2020, 460, 125103, https://doi.org/10.1016/j.optcom.2019.125103. 